Pesq. Vet. Bras. 35(5):443-447, maio 2015 DOI: $10.1590 / \mathrm{S} 0100-736 \mathrm{X} 2015000500009$

\title{
Equine proliferative enteropathy on a Brazilian farm ${ }^{1}$
}

\author{
Michelle P. Gabardo², José P.H. Sato², Talita P. Resende ${ }^{2}$ and Roberto M.C. Guedes ${ }^{2 *}$
}

\begin{abstract}
Gabardo M.P., Sato J.P.H., Resende T.P. \& Guedes R.M.C. 2015. Equine proliferative enteropathy on a Brazilian farm. Pesquisa Veterinária Brasileira 35(5):443-447. Departamento de Clinica e Cirurgia Veterinária, Escola de Medicina Veterinária, Universidade de Federal de Minas Gerais, Av. Antônio Carlos 6627, Pampulha, Belo Horizonte, MG 31270-901, Brazil. E-mail: guedesufmg@gmail.com

Lawsonia intracellularis infection on a horse farm in the Midwest region of Brazil is described. Thirty-nine foals a few days to months old from a herd with 300 horses, experienced diarrhea with variable characteristics and intensities, weight loss, hyperemic mucous membranes and dehydration. In foals 3 to 6 months of age, hypoproteinemia associated with submandibular edema were also common. Intestinal fragments of a 7-month-old foal were sent to an animal disease laboratory for diagnosis. The observed macroscopic lesions were hyperemic serosa, thickening of the intestinal wall with a corrugation, thickening of the mucosa folds and reduction of intestinal lumen. Histological analysis of the small and large intestine revealed enterocyte hyperplasia of the crypts associated with diffuse marked decrease in the number of goblet cells and positive L. intracellularis antigen labeling by immunohistochemistry. Three out of 11 animals of the same property were seropositive for L. intracellularis, demonstrating the circulation of the agent throughout the farm, but none were PCR positive in fecal samples. Based on clinical signs and pathological findings, the diagnosis of equine proliferative enteropathy was confirmed.
\end{abstract}

INDEX TERMS: EPE, Equine proliferative enteropathy, Lawsonia intracellularis, foals, diarrhea, IPMA.

RESUMO.- [Enteropatia proliferativa em um haras brasileiro.] Descreve-se a infecção por Lawsonia intracellularis em uma propriedade na região Oeste do Brasil. Em um rebanho de 300 equinos, 39 potros com poucos dias de vida à 21 meses apresentaram diarreia de características e intensidades variáveis, com perda de peso e desidratação. Em potros com três a seis meses de idade, hipoproteinemia associada a edema submandibular também foram frequentes. Fragmentos intestinais de um potro de 7 meses foram enviados ao laboratório de patologia animal para diagnóstico. Na macroscopia foi observada hiperemia de serosa e moderado espessamento de parede intestinal. Na histologia do intestino delgado existia hiperplasia de enterócitos de criptas difusa intensa com redução marcante de células caliciformes e marcação positiva na imuno-histoquímica

\footnotetext{
${ }^{1}$ Received on April 16, 2015.

Accepted for publication on May 12, 2015.

${ }^{2}$ Departamento de Clinica e Cirurgia Veterinária, Escola de Medicina Veterinária, Universidade de Federal de Minas Gerais (UFMG), Av. Antônio Carlos 6627, Pampulha, Belo Horizonte, MG 31270-901, Brazil. E-mails: mi_gabardo@hotmail.com,zpsato@hotmail.com, talitaresendevet@gmail.com; *Corresponding author: guedesufmg@gmail.com
}

para L. intracellularis. Na sorologia de 11 animais da mesma propriedade, três foram positivos. Já a PCR foi negativa para todos os animais. Com base nos sinais clínicos e nos achados patológicos confirmou-se o diagnóstico de enteropatia proliferativa equina, associada a sorologia positiva que demonstrava circulação do agente na propriedade.

TERMOS DE INDEXAÇÃO: Enteropatia proliferativa equina, Lawsonia intracellularis, potro, IPMC.

\section{INTRODUCTION}

Lawsonia intracellularis, an obligate intracellular pathogen, is the etiological agent of proliferative enteritis (PE) (Pusterla \& Gebhart 2013). The first reported incidence in horses was described by Duhamel \& Wheeldon in 1982, but it was not until 1996 that Williams et al. (1996) characterized the disease and associated lesions with L. intracellularis infection using immunohistochemistry and electron microscopy (Williams et al. 1996).

Equine proliferative enteropathy (EPE) is an emerging disease in foals and has a higher incidence in 2- to 9-month-old animals. Infected animals become lethargic rapid and severe weight loss, cramps, diarrhea, ascites, and swelling 
in the submandibular region and the forelimb distal portion. Lesions compatible with EPE are more often restricted to the small intestine. Necropsies reveal the most characteristic lesion to be a thickening of the bowel wall due to the thickening of the mucosa. Microscopically, hyperplasia of immature crypt enterocytes in the absence of goblet cells are observed.

The number of EPE cases described in the literature is increasing, with reports of occurrence in North America, Europe, South Africa and Japan (Pusterla \& Gebhart 2013). Currently, there have been only 2 reports of the presence of L. intracellularis in horses in Brazil: the first was a serological and PCR study that determined the prevalence of the disease on farms in the state of Minas Gerais (Guimarães-Ladeira et al. 2009). Although there were serological and PCR positive results, no clinical symptoms of the disease were observed among the studied animals. The second report was in the state of Rio de Janeiro, which confirmed the presence of EPE through clinical symptoms and positive PCR results from stool samples; therapeutic treatment and cure of the infected animal followed (Guttmann et al. 2014). Therefore, even though circulation of L. intracellularis and clinical cases of EPE have been observed, no associated mortality has yet been detected in equine in Brazil. Here, we describe the first case in Brazil of EPE with clinical signs, serological results, gross and histological lesions and immunohistochemistry confirmation of $L$. intracellularis infection.

\section{MATERIALS AND METHODS}

The farm had a herd of approximately 300 horses of different ages and sex. Foals were generally weaned between 4 and 7 months of age, and then grouped in batches of approximately 35 individuals sorted according to age. The foals were handled routinely in the same facilities as other individuals of various ages. Pregnant mares, non-pregnant mares with foals and weanling foals were frequently bought without prior examination for Lawsonia intracellularis. However, none of the animals introduced to the farm over the past several years showed signs of having diarrhea. All animals were dewormed 5 to 6 times annually using an alternating program of doramectin and association of ivermectin and pyrantel pamoate or praziquantel. In this farm cases of diarrhea of variable severity and characteristics were reported every year and involved foals of different ages.

In May of 2013, fragments of the small and large intestines, of a 7-month-old horse that died, were fixed in $10 \%$ formalin and submitted for histopathology to Laboratory of Veterinary Pathology in Veterinary School, Universidade Federal de Minas Gerais. Samples were processed according to routine histological methods and stained by hematoxylin-eosin. An immunohistochemical assay was performed using labeled streptavidin (DAKO, LSAB 675), and polyclonal anti-L. intracellularis at a concentration of 1:30,000 (Guedes et al. 2009).

Eleven sera and fecal samples from this group of foals were received previously for serological analysis and PCR testing, respectively, for detection of L. intracellularis (Jones et al 1993). Serum samples were tested with an immunoperoxidase monolayer assay (IPMA) (Guedes et al. 2009) with serum dilution of 1:60. Stool samples from the same animals were also submitted to other laboratories for PCR analysis to search for Clostridium spp., Clostridium perfringens, and Salmonella sp., scanning electron microscopy analysis to search for coronavirus and parasitological testing and PCR analysis to search for Cryptosporidium spp.

\section{RESULTS}

Among 39 foals, between the ages of a few days to 21 months, 9 animals born in 2011 and 30 born in 2012 exhibited clinical signs of semisolid evolving to watery diarrhea, body temperature varying between $39.5^{\circ} \mathrm{C}$ to $41.0^{\circ} \mathrm{C}$ in the first 48 hours, a lack of appetite and dehydration. In foals 3 to 6 months of age, hypoproteinemia associated with submandibular edema were frequently observed. Clinical signs lasted from a few days to several weeks.

In animals with clinical signs of diarrhea, treatment with antibiotics (gentamicin), antispasmodic with antipyretic (Buscopan ${ }^{\circledR}$ ) combined with supportive treatment with serotherapy (Lactated Ringer's solution, 5\% dextrose and potassium chloride) and omeprazole ${ }^{\circledR}$ was performed. Animals showed improvement in clinical symptoms, including decreasing fever and mucosal hyperemia, following treatment, but there were no significant changes in diarrheal signs. In foals with hypoproteinemia, erythromycin was administered in doses of $25 \mathrm{mg} / \mathrm{Kg}$ b/w every 6 hours for 28 days and, in severe cases, new applications were made with an interval of 7 days. Approximately $30 \%$ of ani-

Table 1. Examinations performed for certain causative agents of diarrhea in stool and serum samples of 11 foals

\begin{tabular}{|c|c|c|c|c|c|c|c|c|}
\hline \multirow[t]{2}{*}{ Foal $^{\mathrm{a}}$} & \multirow[t]{2}{*}{$\begin{array}{c}\text { Age } \\
\text { (months) }\end{array}$} & \multirow[t]{2}{*}{$\begin{array}{l}\text { Corona } \\
\text { Virus }^{\text {b }}\end{array}$} & \multirow[t]{2}{*}{ C. perfringens ${ }^{c}$} & \multirow[t]{2}{*}{ Salmonella sp. ${ }^{\mathrm{c}}$} & \multirow[t]{2}{*}{ Crypt. } & \multicolumn{2}{|c|}{$\begin{array}{l}\text { Lawsonia } \\
\text { intracelullaris }\end{array}$} & \multirow[t]{2}{*}{ Diarrhea } \\
\hline & & & & & & Sorology & PCR & \\
\hline 1 & 19 & + & - & - & - & + & - & No \\
\hline 2 & 21 & + & - & - & - & + & - & No \\
\hline 3 & 19 & & & - & - & - & - & No \\
\hline 4 & 19 & & - & - & - & - & - & No \\
\hline 5 & 16 & & - & - & - & - & - & No \\
\hline 6 & 17 & & & - & - & + & - & No \\
\hline 8 & 3 & & & - & - & - & - & Yes \\
\hline 9 & 3 & & - & - & - & - & - & Yes \\
\hline 21 & 3 & & & & & - & - & Yes \\
\hline 22 & 4 & & & & & - & - & Yes \\
\hline 23 & 3 & & & & & - & - & Yes \\
\hline
\end{tabular}

a Foals 9, 21, 22 and 23 were being treated in the period of feces collection, ${ }^{\mathrm{b}}$ Detected by scanning electron microscopy, ${ }^{\mathrm{c}}$ Detected by PCR, ${ }^{\mathrm{d}}$ Cryptosporidium spp. 
mals showed signs of clinical improvement following this treatment.

Three foals were found to be seropositive for L. intracellularis. All foals tested negative for L. intracellularis in PCR analysis of fecal samples. The results of the other agentes are shown in Table 1.
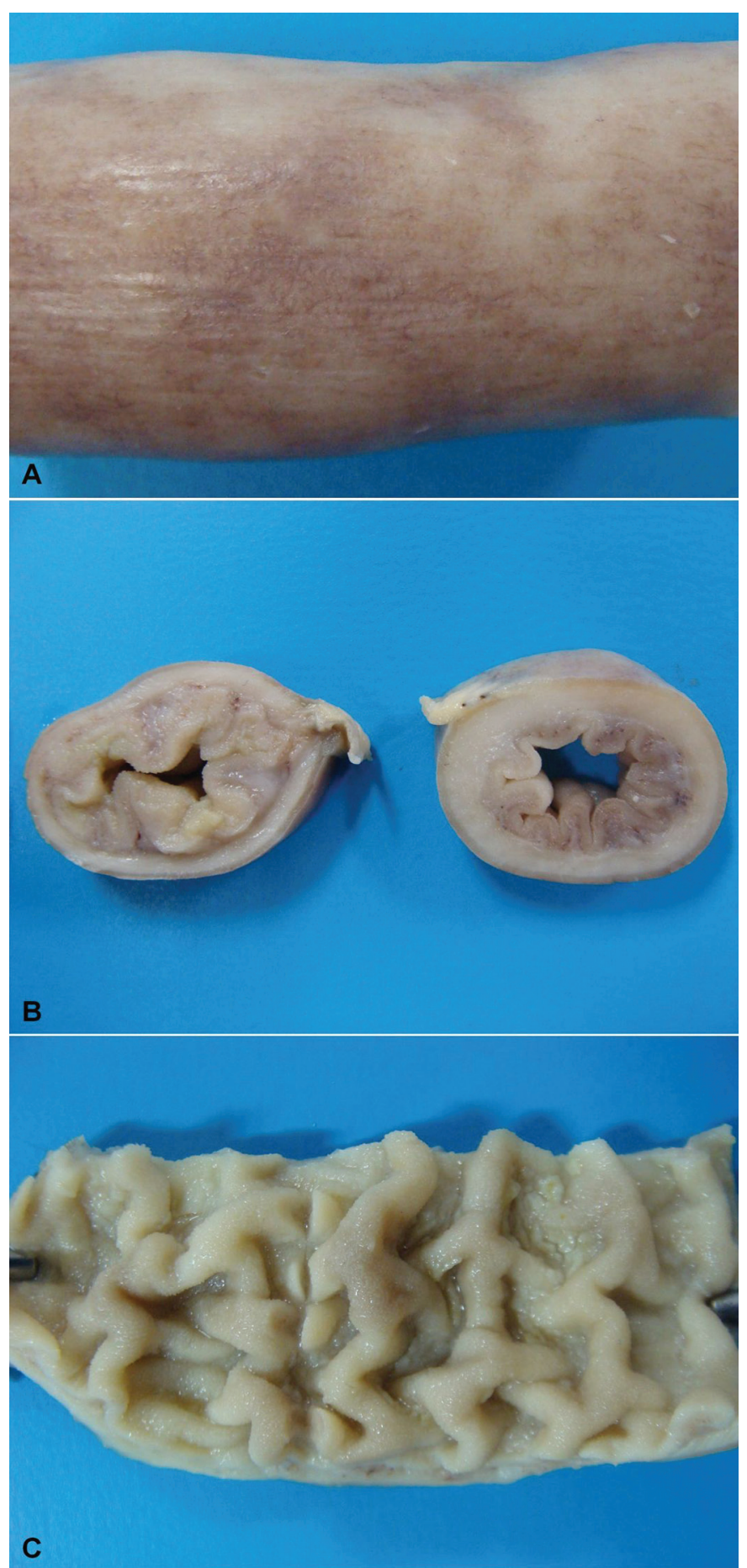

Fig.1. Fragments of intestine, fixed in $10 \%$ formalin, of a 7 -month-old horse diagnosed with EPE. (A) Serous with multifocal to coalescing hyperemia. (B) Cross-section of a small bowel segment with a thick wall and decreased intestinal lumen due to mucosal thickening. (C) Longitudinal section of a small bowel segment showing the thickening of the intestinal folds.
Seven of the 39 foals had clinical signs of diarrhea, and 3 of these animals died. A 7-month-old foal died 4 days after the onset of clinical signs, and intestinal samples from this foal were submitted to the Laboratory. Macroscopically, a large volume of blood-tinged fluid was observed in the peritoneal cavity. Small intestine serosa was hyperemic (Fig.1A). Thickening of the intestinal wall was associated with a clear corrugation and thickening of the mucosa folds and reduction of intestinal lumen (Fig.1B). The mucosa was heavily corrugated, characterizing thickening of intestinal folds (Fig.1C).

Histological analysis of the duodenum, jejunum, ileum and large intestine demonstrated enterocyte hyperplasia of the crypts associated with intense diffuse decrease in abundance (Fig.2A). Rare crypts were dilated and the lumen found to be filled with cell debris and neutrophils (crypt abscess). In addition, crypts were present in some areas of the submucosa (Fig.2B). Immunohistochemistry staining demonstrated antigen labeling at the cytoplasmatic apex of enterocytes and in macrophages in the lamina propria of the duodenum, ileum and large intestine (Fig.2C).

\section{DISCUSSION}

Reported clinical signs and macro- and microscopic findings, all consistent with the literature (Lester 2001, Pusterla et al. 2010, Vannucci et al. 2012) associated with positive immune staining for Lawsonia intracellularis allowed us to reach the diagnosis of equine proliferative enteropathy (EPE). Unlike pigs, in which lesions and immunostaining are more highly concentrated in the final third of the small intestine, in horses, these lesions can also be found in the duodenum, as reported in this case. The lesions of the large intestine are less frequent, but in our case, histologic lesions compatible with EPE were found in the large intestine. The ages of affected animals ranged from a few days to 21 months of age, although diarrhea associated with hypoproteinemia and submandibular edema had been observed more frequently in foals 3 to 6 months old, an age group in which animals are more susceptible to and affected by L. intracellularis (Pusterla et al. 2010, Vannucci et al. 2012). This predisposition is most likely associated with the decline of maternal antibodies (Pusterla et al. 2008a), as well as stressors such as weaning, moving to new paddocks and barns, deworming and/ or vaccination programs and/or early conditioning programs (Frazer 2008), which were performed at this farm.

Three and 4 month old foals (animals 8, 9, 21, 22 and 23) had diarrhea at the time of feces collection, but serology and PCR showed them to be negative. PCR cannot, however, detect the low bacterial elimination in feces of recently infected or subclinical animals, or in foals that have experienced prolonged disease or are under antibiotic treatment (Dauvillier et al. 2006, Pusterla \& Gebhart 2013). According to the reports, L. intracellularis fecal excretion detection stops or ceases 4-6 days after the beginning of doxycycline (Pusterla \& Gebhart 2013) and erythromycin (Dauvillier et al. 2006) administration. In inoculated animals, elimination of $L$. intracellularis in feces was first detected by PCR analysis 12 to 18 days post-inoculation and continued for 7 to 21 days (Pusterla \& Gebhart 2013, 


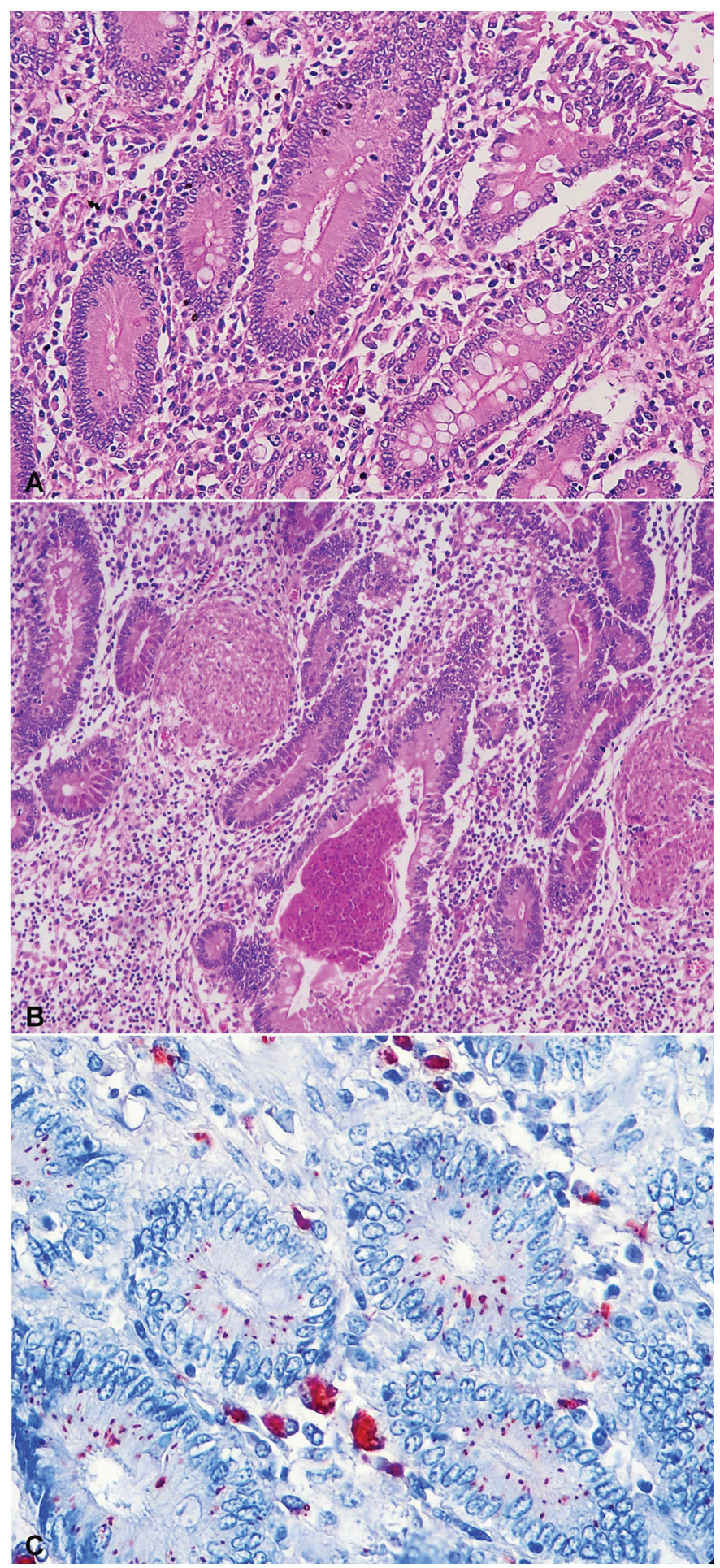

Fig.2. (A) Histological section of the small and large intestines of a 7-month-old horse with intense hyperplasia of crypt enterocytes associated with intense marked decrease of goblet cells next to normal crypts with the monolayer of enterocytes and numerous goblet cells. HE, obj.100x. (B) Histological section of small intestine crypt hyperplasia associated with a reduction of goblet cells and dilated crypt filled with cellular debris and neutrophils (crypt abscess), and presence of crypts in the submucosa (HE, obj.100x. (C) Histological section of the small intestine of the horse, with red indicating positive for L. intracellularis in the cytoplasm of crypts enterocytes, enterocytes surface villi and in macrophages in the lamina propria. AEC, obj.100x.
Pusterla et al. 2010). Positive serologic results occur 14 to 21 days after exposure (Pusterla \& Gebhart 2013, Pusterla et al. 2010), as negative results are expected in the early stage of the disease, when the humoral immune response is too insubstantial to be detected by serology (Pusterla \& Gebhart 2013). Thus, the period during which blood samples were collected may also have influenced the results. Seropositivity for $L$. intracellularis in animals that tested negative in PCR analysis of fecal samples can be explained by the sensitivity of the last technique and/or by the course of the infection. There are many PCR inhibitors in fecal material that reduce the sensitivity of the technique and, as a result, the amount of shed bacteria in the feces could be below the detection threshold. In addition, serum antibodies against $L$. intracellularis last much longer than the bacteria fecal shedding (Pusterla et al. 2008a).

Despite the absence of a definitive EPE diagnosis, the death of several foals that exhibited signs of diarrhea can be explained by the application of the antibiotic gentamycin. This antimicrobial is not effective in the treatment of EPE (Schumacher et al. 2000, Vannucci et al. 2012, Wuersch et al. 2006) because its active property has a high minimum inhibitory concentration (MIC) for L. intracellularis (McOrist et al. 1995). In animals with hypoproteinemia, erythromycin doses were followed by clinical improvement in some infected animals, and treatment with erythromycin was effective for EPE in other reports (Bihr 2003, Lavoie et al. 2000, Schumacher et al. 2000) and is generally considered the drug of choice for the treatments of suspected cases. Disease progression varies from days to weeks, and the prognosis for recovery is good when diagnosis is timely and appropriate treatment programs are performed. Late diagnosed or untreated cases, on the other hand, generally result in the animal's death (Pusterla \& Gebhart 2013). The seropositivity rate in our study was $27 \%$, a rate lower than that of other studies (Pusterla et al. 2008a) (29.7\% and 33.8\%) conducted at farms with EPE cases. However, the first serum dilution used by that author was 1:30, while serological tests in our lab were 1:60, as this dilution showed the least nonspecific labeling. Epidemiological investigations on farms with clinical cases indicate that $10-65 \%$ of healthy adult horses and foals are seropositive for L. intracellularis (Frazer 2008, Pusterla et al. 2009). The percentage of positive animals ranged from $3.57 \%$ to $16.67 \%$ in Minas Gerais herds, while the properties had no cases of clinical disease, which justifies lower rates of seropositive (Guimarães-Ladeira et al. 2009).

The infection of the foals discussed in this report may have occurred through contact with the feces of other horses infected with L. intracellularis due to the daily use of the same facilities by horses of all ages and/or from the introduction of new animals without prior examination for the agent. None of the animals entering the property during the past year exhibited clinical signs of EPE, but the absence of clinical signs in equine does not rule out the chance of a possible carrier and thus a possible source of contamination for other animals on the farm (Guimarães-Ladeira et al. 2009, Page et al. 2011, Pusterla et al. 2010). EPE is not included on differentials enteric diseases in horses in Brazil, and there are many neglected positive animals. 
Wild and domestic animals such as dogs, cats, opossums (Didelphis sp.), and bush dog (Canis thous) known to inhabit or visit the property may also be sources of contamination. Bacterial DNA has been detected in the feces of domestic and wild animals trapped in farms where EPE has occurred (Pusterla et al. 2008b, Pusterla et al. 2012). Lavoie et al. (2000) reported the ingress of the agent in a farm where new horses were not introduced and resident horses did not come into contact with pigs, suggesting contamination by wild animals. However, the role of these animals in the disease epidemiology is not well understood. Although the animals have no direct contact with pigs, the role of pigs in the introduction of the agent to farms and the subsequent contamination of horses is controversial. Al-Ghamdi et al. (2012) reproduced proliferative enteropathy (EP) in 2-month-old foals using a pure culture of $L$. intracellularis and intestinal mucosa homogenates obtained from experimentally infected pigs. However, Vannucci et al. (2012) did not observe the same results, as pigs infected with equine isolated and foals infected with L. intracellularis isolated from pigs showed no clinical signs, decline in performance, pathological changes or hypoproteinemia, suggesting adaptation to the host.

\section{CONCLUSIONS}

Equine proliferative enteropathy is present in horses in Midwest Brazil, and despite the report of a clinical case of the disease and the detection of Lawsonia intracellularis in feces and via serological analysis in foals in other Brazilian states, the disease remains neglected in the differential diagnosis of other enteric diseases in foals.

This report describes the death of a foal caused by the disease and contributes to the understanding of the behavior of the disease in the field, with the description of clinical signs, lesions, treatment and epidemiology, as well as presenting different diagnostic techniques that can be employed to detect the agent.

Declaration of conflicting interests.- The author(s) declare no potential conflicts of interest with respect to the research, authorship, and/or publication of this article.

Acknowledgements.- The authors thank CNPq, CAPES and Fapemig for their financial support. RMCG is a recipient of a fellowship from CNPq.

\section{REFERENCES}

Al-Ghamdi G.M., Guedes R.M.C., Sage A.M., Hayden D.W., Neubauer A. \& Ames T.R. 2012. Reproduction of proliferative enteropathy in foals using porcine intestinal mucosal homogenate. Bulgarian J. Vet. Med. 15(4):273-282.

Bihr T.P. 2003. Protein-losing enteropathy caused by Lawsonia intracellularis in a weanling foal. Can. Vet. J. 44(1):65-66.

Dauvillier J., Picandet V., Harel J., Gottschalk M., Desrosiers R., Jean D. \& Lavoie J.-P. 2006. Diagnostic and epidemiological features of Lawsonia intracellularis enteropathy in 2 foals. Can. Vet. J. 47(7):689-691.
Frazer M.L. 2008. Lawsonia intracellularis infection in horses: 2005-2007. J. Vet. Intern. Med. 22(5):1243-1248.

Guedes R.M.C., Franca S.A., Machado G.S., Blumer M.A. \& Da Costa Cruz Jr E.C. 2009. Use of tylvalosin-medicated feed to control porcine proliferative enteropathy. Vet. Rec. 165(12):342-345.

Guimarães-Ladeira C.V., Palhares M.S., Oliveira J.S., Ramirez M.A. \& Guedes R.M.C. 2009. Shedding and serological cross-sectional study of Lawsonia intracellularis in horses in the state of Minas Gerais. Brazil. Equine Vet. J. 41(6):593-596.

Guttmann P.M., Viscardi V., Lessa D.A.B. \& Guedes R.M.C. 2014. Equine Proliferative Enteropathy Caused by Lawsonia intracellularis in a Foal in Brazil. J. Equine Vet. Sci. 34(5):701-703.

Jones G.F., Ward G.E., Murtaugh M.P., Lin G. \& Gebhart C.J. 1993. Enhanced detection of intracellular organism of swine proliferative enteritis, Ileal symbiont intracellularis, in faeces by polymerase chain reaction. J. Clin. Microbiol. 31(10):2611-2615.

Lavoie J.P., Drolet R., Parsons D., Leguillette R., Sauvageau R., Shapiro J., Houle L., Hallé G. \& Gebhart C.J. 2000. Equine proliferative enteropathy: a cause of weight loss, colic, diarrhea and hypoproteinaemia in foals on the breeding farms in Canada. Equine Vet. J. 32(5):418-425.

Lester G.D. 2001. Infectious diarrhea in foals. Proceedings of the $47^{\text {th }}$ AARP Annual Convention, San Diego, CA, p.468-471.

McOrist S., Mackie R.A. \& Lawson G.H. 1995. Antimicrobial susceptibility of ileal symbiont intracellularis isolated from pigs with proliferative enteropathy. J. Clin. Microbiol. 33(5):1314-1317.

Page A.E., Slovis N.M., Gebhart C.J., Wolfsdorf K., Mapes S.M. \& Pusterla N. 2011. Serial use of serologic assays and fecal PCR assays to aid in identification of subclinical Lawsonia intracellularis infection for targeted treatment of Thoroughbred foals and weanlings. J. Am. Vet. Med. 238(11):1482-1489.

Pusterla N. \& Gebhart C. 2013, Lawsonia intracellularis infection and proliferative enteropathy in foals. Vet. Microbiol. 167:34-41.

Pusterla N., Higgins J.C., Smith P., Mapes S. \& Gebhart C. 2008a. Epidemiological survey on farms with documented occurrence of equine proliferative enteropathy due to Lawsonia intracellularis. Vet. Rec. 163(5):156-8.

Pusterla N., Jackson R., Wilson R., Collier J., Mapes S. \& Gebhart C. 2009. Temporal detection of Lawsonia intracellularis using serology and real-time PCR in Thoroughbred horses residing on a farm endemic for equine proliferative enteropathy. Vet. Microbiol. 136(1/2):173-176.

Pusterla N., Mapes S. \& Gebhart C. 2012. Further investigation of exposure to Lawsonia intracellularis in wild and feral animals captured on horse properties with equine proliferative enteropathy. Vet. J. 194(2):253-255.

Pusterla N., Mapes S., Rejmanek D. \& Gebhart C. 2008b. Detection of Lawsonia intracellularis by Real-time PCR in the feces of free-living animals from equine farms with documented occurrence of Equine proliferative enteropathy. J. Wildl. Dis. 44(4):992-998.

Pusterla N., Wattanaphansak S., Mapes S., Collier J., Hill J., Difrancesco M. \& Gebhart C. 2010. Oral infection of weanling foals with an equine isolate of Lawsonia intracellularis, agent of Equine proliferative enteropathy. J. Vet. Intern. Med. 24:622-627.

Schumacher J., Schumacher J., Rolsma M., Brock K.V. \& Gebhart C.J. 2000. Surgical and medical treatment of an Arabian filly with proliferative enteropathy caused by Lawsonia intracellularis. J. Vet. Intern. Med. 14(6):630-632.

Vannucci F.A., Pusterla N., Mapes S.M. \& Gebhart C. 2012. Evidence of host adaptation in Lawsonia intracellularis infections. Vet. Res. 43:53.

Williams N.M., Harrison L.R. \& Gebhart C.J. 1996. Proliferative enteropathy in a foal caused by Lawsonia intracellularis-like bacterium. J. Vet. Diagn. Invest. 8(2):254-256

Wuersch K., Huessy D., Koch C. \& Oevermann A. 2006, Lawsonia intracellularis proliferative enteropathy in a filly. J. Vet. Med. A, Physiol. Pathol. Clin. Med. 53(1):17-21. 